\title{
Preoperative and Early Postoperative Quality of Life Predict Survival in Potentially Curable Patients with Esophageal Cancer
}

\author{
Mark van Heijl ${ }^{1}$, Mirjam A. G. Sprangers, $\mathbf{P h D}^{2}$, Angela G. E. M. de Boer, $\mathbf{P h D}^{3}$, Sjoerd M. Lagarde, $\mathbf{P h D}^{1}$, \\ Hans B. Reitsma, $\mathrm{PhD}^{4}$, Olivier R. C. Busch, $\mathrm{PhD}^{1}$, Hugo W. Tilanus, $\mathrm{PhD}^{5}$, Jan J. B. van Lanschot, $\mathrm{PhD}^{1,5}$, \\ and Mark I. van Berge Henegouwen, $\mathbf{P h D}^{1}$
}

\begin{abstract}
${ }^{1}$ Department of Surgery, G4-115, Academic Medical Centre, University of Amsterdam, Amsterdam, The Netherlands; ${ }^{2}$ Department of Medical Psychology, Academic Medical Centre, Amsterdam, The Netherlands; ${ }^{3}$ Coronel Institute of Occupational Health, Academic Medical Centre, Amsterdam, The Netherlands; ${ }^{4}$ Department of Clinical Epidemiology, Biostatistics and Bioinformatics, Academic Medical Centre, Amsterdam, The Netherlands; ${ }^{5}$ Department of Surgery, Erasmus Medical Centre, Rotterdam, The Netherlands
\end{abstract}

\begin{abstract}
Background. In patients with esophageal cancer, evidence for prognostic significance of preoperative quality of life (QoL) is limited, while the prognostic significance of postoperative QoL has not been investigated at all.

Aim. To determine whether preoperative and postoperative QoL measurements can predict survival independently from clinical and pathological factors, in patients with potentially curable esophageal adenocarcinoma.

Methods. A randomized controlled trial was performed from 1994 to 2000 in two academic medical centres, comparing transthoracic and transhiatal esophagectomy. QoL questionnaires were sent before and 3 months after surgery (Medical Outcome Study Short Form-20 and Rotterdam Symptom Checklist). Uni- and multivariate Cox regression analyses were used to examine firstly the prognostic value of preoperative QoL and several clinical factors, and secondly of postoperative QoL, several clinical factors, and pathological staging.

Results. Out of 220 randomized patients, 199 participated in the QoL-study. In the multivariate preoperative model physical symptom scale $(p=0.021)$, tumor length $(p=$ $0.034)$, and endosonographic T-stage $(p=0.003)$ were predictive for overall survival. In the postoperative multivariate analysis, social functioning $(p=0.035)$, pain
\end{abstract}

(C) The Author(s) 2009. This article is published with open access

at Springerlink.com

First Received: 29 June 2009;

Published Online: 15 October 2009

M. I. van Berge Henegouwen

e-mail: m.i.vanbergehenegouwen@amc.uva.nl
( $p=0.026)$, and activity level $(p=0.037)$ predicted survival, besides pathological T-stage $(p<0.001)$ and $\mathrm{N}$-stage $(p<0.001)$.

Conclusion. In the present paper the first large consecutive series of potentially curable esophageal cancer patients is presented in whom prospectively collected QoL data before and after potentially curative surgical resection were used to predict survival. Both preoperative (physical symptoms) and postoperative (social functioning, pain, and activity level) QoL subscales are independent predictors of survival in potentially curable patients with esophageal adenocarcinoma.

Surgery is considered to be the best curative treatment for patients with advanced esophageal cancer, whether or not preceded by neoadjuvant therapy. ${ }^{1}$ Despite many improvements in oncological treatment and perioperative care, survival remains poor. ${ }^{2}$ Even after potentially curative esophagectomy 5 -year survival rates rarely exceed $40 \% .^{3-5}$ Long-term survival depends on several factors including well-known clinical and pathological parameters. ${ }^{6}$ Prediction of long-term survival is of great importance because a major proportion of patients want a realistic and individualized approach from the cancer specialist when discussing their prognosis. ${ }^{7,8}$

Recently, patient-reported outcomes have been studied as prognostic factors for survival in oncological patients. ${ }^{9}$ In these studies pretreatment quality of life (QoL) has been shown to be significantly associated with survival in various types of cancer patients, such as those with colorectal, breast, prostate, and lung cancer. ${ }^{10-13}$ However, for patients with esophageal cancer, solid evidence for prognostic 
significance of preoperative QoL is still limited. ${ }^{14-16}$ The prognostic value of posttreatment $\mathrm{QoL}$ for this group of cancer patients has not been investigated at all.

The aim of the present study is to examine to what extent pre- and postoperative QoL subscales are able to predict survival, independently from well-known clinical and pathological prognostic factors, in a large homogeneous series of patients with potentially curable esophageal adenocarcinoma.

\section{PATIENTS AND METHODS}

\section{Patients}

Eligible patients with histologically confirmed adenocarcinoma of the distal esophagus or gastric cardia substantially involving the distal esophagus without evidence of distant dissemination and/or local irresectability were randomly assigned to undergo transhiatal esophagectomy or transthoracic esophagectomy with extended en bloc lymphadenectomy. Patients were included between April 1994 and February 2000, in two academic medical centres. The study was approved by the medical ethics committees. Patients were older than 18 years and in adequate condition as indicated by their assignment to American Society of Anesthesiologists (ASA) class I or II. ${ }^{17}$ Exclusion criteria were previous or coexisting cancer, neoadjuvant chemotherapy or radiation therapy, recurrent laryngeal nerve palsy, and the impossibility to construct a gastric tube. Details of design, surgical technique, and clinical results of this trial have been reported earlier. ${ }^{4,18}$ Summarizing the most important results of this trial, transhiatal esophagectomy proved to be associated with lower morbidity than transthoracic esophagectomy with extended en bloc lymphadenectomy. There was no significant overall survival benefit for either approach, but compared with limited transhiatal resection, extended transthoracic esophagectomy for type I esophageal adenocarcinoma showed an ongoing trend towards better 5-year survival. Moreover, patients with a limited number of positive lymph nodes in the resection specimen seemed to benefit from an extended transthoracic esophagectomy. Clinical data was collected prospectively.

\section{Quality-of-Life Measurement}

QoL data were gathered by using self-administered QoL questionnaires, which were sent to the patients before and 3 months after surgery. If the patient did not return the questionnaire, he or she received one reminder.

Generic QoL was measured with the Medical Outcome Study Short Form-20 (MOS SF-20), a reliable and valid standardized measure containing 20 items measuring health perceptions, physical functioning, role functioning, social functioning, mental health, energy, and bodily pain. ${ }^{19}$ The MOS SF-20 was scored on a five-point scale. All raw scales were linearly converted to a 0-100 scale, with higher scores indicating better QoL, except for bodily pain where a higher score indicated more pain.

Disease-specific QoL was measured by the Rotterdam Symptom Checklist (RSCL), an extensively validated self-report questionnaire designed for use with cancer patients. ${ }^{20,21}$ We adapted the original RSCL by adding nine physical symptoms specific to esophageal carcinoma (dysphagia, loss of taste, weight loss, early satiety, blownup feeling, hoarseness, pain behind chest bone, food not going down, and nocturnal coughing) and omitting seven less relevant physical items (burning eyes, dry mouth, hair loss, shivering, tingling hands or feet, painful muscles, and lower back pain). ${ }^{22}$ The adapted RSCL contained 41 items, covering 25 physical symptom items, 7 psychological symptom items, 8 items on activity level, and 1 item measuring global QoL. Answers were rated on a four-point response scale, except for the global QoL item, which was assessed on a seven-point scale. All raw scales were linearly converted to a 0-100 scale, with higher scores indicating better QoL.

\section{Follow-Up}

All patients were seen at the outpatient clinic at intervals of 3-4 months during the first 2 years and every 6 months for 3 more years. After 5 years, follow-up data were obtained by telephone from the patients or his or her family practitioner. The last check on follow-up of all patients was performed in February 2005. Recurrence of disease was diagnosed on clinical grounds. However, whenever a relapse was suspected, radiologic, endoscopic or histologic confirmation was sought.

\section{Statistical Analysis}

Survival times were calculated from time of randomization to time of death from any cause or time to last follow-up visit (at which time data were censored). Disease-free survival was counted up to time of first relapse and patients were censored at time of their last visit or when they died of non-disease-related causes without previous relapse. Survival curves were constructed by the Kaplan-Meier method.

In the first part of the statistical analysis, univariate Cox regression analysis was performed using all preoperative QoL subscales and several well-known preoperative clinical factors including age, sex, tumor length, weight loss, and endosonographic tumor-node-metastasis (TNM) stage 
(uTNM). All variables with $p<0.05$ were included in multivariate analysis. Using backward elimination a final multivariate model was created keeping only variables with $p<0.05$. In case there was the problem of monotone likelihood because of zero events in any of the strata of the predictors, Cox regression analysis with Firth penalization was used. ${ }^{23}$ Cox regression analysis was performed for overall and disease-free survival. Since pathological stage is not available preoperatively, we included only clinical factors actually available preoperatively in this part of the analysis.

The second part of the analysis was performed in the same manner, now using the postoperative QoL subscales, and pathological TNM stage of the resection specimen instead of endosonographical TNM stage. We deliberately chose not to analyze all QoL items separately and only to use subscales, to reduce chance-related findings. Statistical analysis was performed with the Statistical Package for the Social Sciences software version 15.0 (SPSS, Chicago, IL).

\section{RESULTS}

Between April 1994 and February 2000, 220 patients were randomized for transhiatal or transthoracic esophagectomy. A total of 199 patients agreed to participate in the QoL study. Fourteen patients were enrolled into the study before the quality-of-life substudy had started, and seven patients were not sent baseline questionnaires because of an administrative error. Patient characteristics are summarized in Table 1. Preoperative QoL-questionnaires were returned by 187 patients $(94.0 \%)$. The QoL questionnaires sent 3 months postoperatively were returned by 178 of the 199 participating patients $(89.4 \%)$; the remaining 9 patients $(4.5 \%)$ deceased within 3 months of surgery.

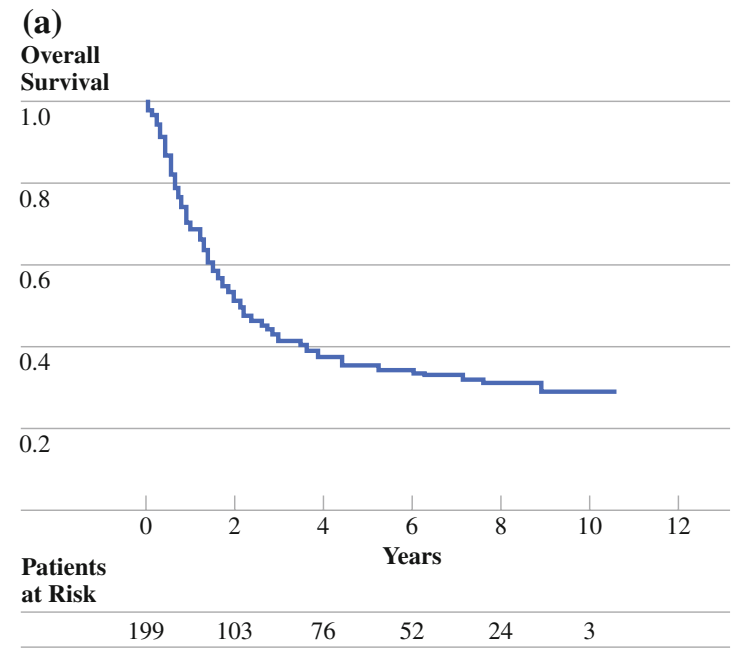

TABLE 1 Clinicopathological characteristics of patients undergoing potentially curative esophagectomy

\begin{tabular}{ll}
\hline & All patients $(n=199)$ \\
\hline Age in years (median) [range] & $64[35-78]$ \\
Sex (male/female) & $173 / 26$ \\
Tumor length in cm (median) [range] & $4[1-12]$ \\
Weight loss (kg) [range] & $4[-7$ to 27] \\
Transhiatal versus transthoracic & $93(47 \%) / 106(53 \%)$ \\
Pathological T-stage & \\
T1 & $35(17.6 \%)$ \\
T2 & $23(11.6 \%)$ \\
T3 & $141(70.9)$ \\
T4 & $0(0 \%)$ \\
Pathological N-stage & \\
N0 & $55(27.6 \%)$ \\
N1 & $144(72.4 \%)$ \\
Returned preoperative questionnaire & $187(94.0 \%)$ \\
Returned postoperative questionnaire & $178(89.4 \%)$ \\
\hline
\end{tabular}

In all patients, the operation was performed at least 5 years earlier, ensuring a minimal potential follow-up of 5 years (range 5-10.6 years). Overall 5-year survival was $35.5 \%$ and 5-year disease-free survival was $32.6 \%$ (Fig. 1a, b).

All of the median QoL subscale scores decreased or remained unchanged after surgery, except for RSCL psychological symptoms (Table 2).

On univariate Cox regression analysis of preoperative QoL scores only RSCL physical symptoms [hazard ratio (HR) $0.654 ; p=0.010]$ and RSCL activity level (HR 0.710; $p=0.033)$ proved significantly predictive for overall survival (Table 3). Weight loss (HR 1.037; $p=0.004$ ), tumor

(b)

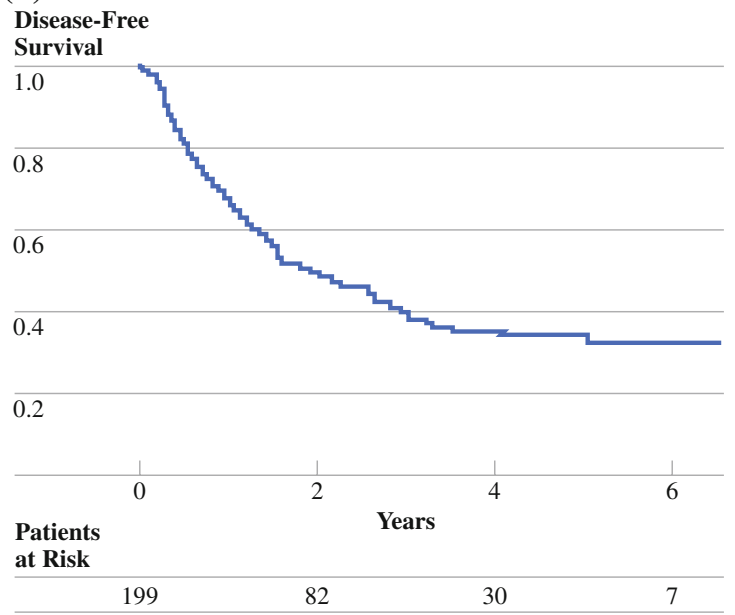

FIG. 1 a Overall survival of all patients undergoing potentially curative esophagectomy. b Disease-free survival of all patients undergoing potentially curative esophagectomy 
TABLE 2 Pre- and postoperative quality of life scores (median and interquartile range) in patients undergoing potentially curative esophagectomy

\begin{tabular}{lll}
\hline & $\begin{array}{l}\text { Preoperative } \\
\text { QoL } \\
(N=187)\end{array}$ & $\begin{array}{l}\text { QoL score 3 months } \\
\text { after surgery } \\
(N=178)\end{array}$ \\
\hline SF-20 physical functioning & $83[50-100]$ & $42[26-67]$ \\
SF-20 health perception & $50[35-70]$ & $42[32-65]$ \\
SF-20 social functioning & $100[60-100]$ & $74[46-100]$ \\
SF-20 energy & $72[60-85]$ & $55[40-75]$ \\
SF-20 pain & $25[0-50]$ & $25[0-50]$ \\
SF-20 role functioning & $100[50-100]$ & $38[0-100]$ \\
SF-20 mental health & $76[64-88]$ & $76[60-92]$ \\
RSCL physical symptoms & $84[80-92]$ & $77[69-85]$ \\
RSCL activity level & $100[93-100]$ & $92[76-100]$ \\
RSCL psychological symptoms & $76[62-90]$ & $81[71-95]$ \\
RSCL global quality of life & $67[50-83]$ & $67[50-83]$
\end{tabular}

$S F-20$ medical outcomes study short form, $R S C L$ Rotterdam symptom checklist

length (HR 1.141; $p<0.001$ ), and endosonographic T-stage (T1 versus T3 HR $0.035 ; p=0.001$ and T2 versus T3 HR $0.805 ; p=0.333$ ) were the clinical factors predictive for overall survival in univariate analysis. Endosonographic Nstage (HR 1.155; $p=0.263$ ) appeared not to be a predictive factor for overall survival. After backward elimination, RSCL physical symptoms (HR 0.668; $p=0.021$ ), tumor length (HR 1.082; $p=0.034)$, and endosonographic Tstage (T1 versus T3 HR $0.050 ; p=0.003$ and T2 versus T3 HR $0.912 ; p=0.717$ ) remained independent prognostic factors in the final multivariate Cox regression model for the preoperative situation (Table 4).

Univariate analysis of the postoperative QoL subscale scores revealed many significant predictors for overall survival: SF20 health perception (HR $0.835 ; p=0.027$ ), SF20 social functioning (HR $0.887 ; p=0.011$ ), SF20 energy (HR 0.785; $p=0.006$ ), SF20 pain (HR 1.196; $p=0.006)$, SF20 mental health (HR 0.818; $p=0.030)$, RSCL physical symptoms (HR 0.724; $p=0.017$ ), RSCL activity level (HR 0.710; $p<0.001$ ), and RSCL global quality of life (HR $0.770 ; p=0.004$ ). Weight loss (HR $1.033 ; p=0.019$ ) and tumor length (HR 1.138; $p<0.001$ ) were again clinical predictors for overall survival on univariate analysis. Pathological T-stage (T1 versus T3 HR 0.084; $p<0.001$ and T2 versus T3 HR $0.487 ; p=0.014$ ) and pathological $\mathrm{N}$-stage (HR 4.617; $p<0.001$ ) were also significantly predictive for overall survival.

After backward elimination, the final multivariate Cox regression model for postoperative parameters showed SF20 social functioning (HR $0.835 ; p=0.035$ ), SF20 pain (HR 1.196; $p=0.026$ ), RSCL activity level (HR 0.785; $p=0.037$ ), pathological T-stage (T1 versus T3 HR 0.122; $p<0.001$ and T2 versus T3 HR 0.430; $p=0.009$ ), and pathological N-stage (HR 3.433; $p<0.001$ ) as independent predictors for overall survival.

Preoperative univariate Cox regression analysis of risk factors for disease-free survival showed again that RSCL physical symptoms (HR 0.641; $p=0.012$ ), RSCL activity level (HR 0.695; $p=0.038$ ), weight loss (HR 1.044; $p=0.001$ ), tumor length (HR 1.159; $p<0.001$ ), and endosonographic T-stage (T1 versus T3 HR 0.020; $p<0.001$ and T2 versus T3 HR $0.868 ; p=0.540$ ) were significant predictors (Table 3). After backward elimination only RSCL physical symptoms (HR $0.641 ; p=0.024$ ), tumor length (HR 1.112; $p=0.008$ ), and endosonographic T-stage (T1 versus T3 HR 0.029; $p<0.001$ and T2 versus T3 HR 0.975; $p=0.918$ ) were significant predictors in the multivariate model for disease-free survival (Table 4).

Postoperative univariate Cox regression analysis for disease-free survival showed the same range of QoL subscales to be significantly predictive as in the univariate analysis for overall survival, except that SF-20 physical functioning was a significant predictor in the disease-free analysis and SF-20 social functioning was not (Table 3). After backward elimination a multivariate model was created including only significant predictors for diseasefree survival: SF-20 pain (HR 1.321; $p=0.001$ ), RSCL activity level (HR 0.724; $p<0.001$ ), pathological T-stage (T1 versus T3 HR $0.124 ; 0=0.001$ and T2 versus T3 HR $0.463 ; p=0.029$ ), and pathological N-stage (HR 3.385; $p=0.001)$.

\section{DISCUSSION}

In the present paper the first large consecutive series of potentially curable esophageal cancer patients is presented in whom prospectively collected QoL data before and after potentially curative surgical resection were used to predict survival. In the preoperative setting only the physical symptom scale was an independent predictor of overall survival, besides the well-known tumor length and endosonographic T-stage. ${ }^{6,24}$ In the postoperative setting the social functioning scale, the pain scale, and the activity level predicted overall survival independently, besides pathological T-stage and N-stage. Analysis for disease-free survival in the postoperative setting showed the pain scale and activity level to be even stronger predictors compared with overall survival.

QoL subscales that were found to predict survival were different preoperatively (physical symptoms) compared with postoperatively (social functioning, pain, and activity level). It might be hypothesized that the predictive strength of preoperative QoL is dominated by the physical symptom subscale, because it probably reflects tumor stage. Perhaps, 


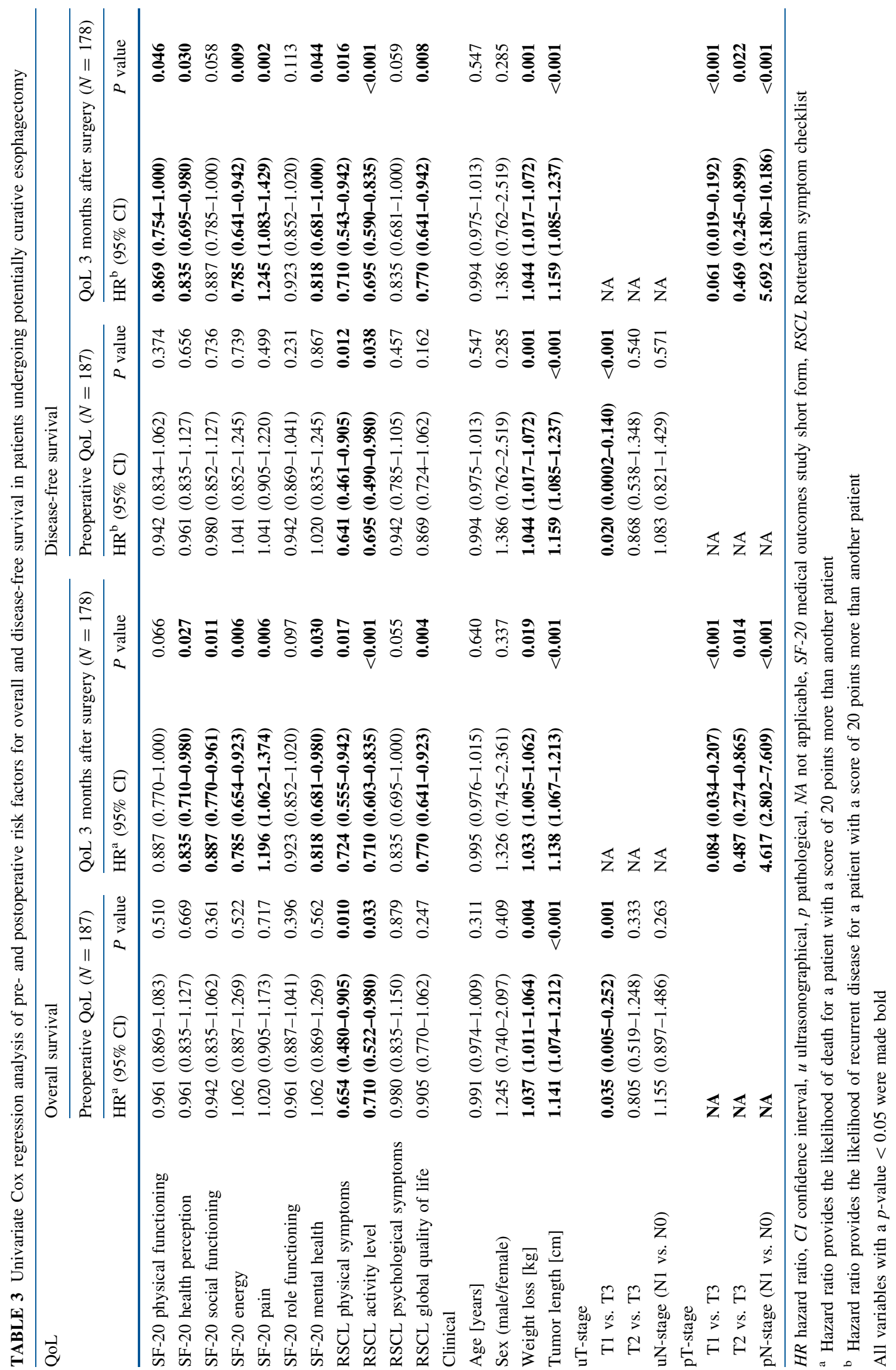


TABLE 4 Multivariate backward elimination Cox regression model of pre- and postoperative risk factors for overall and disease-free survival in patients undergoing potentially curative esophagectomy

\begin{tabular}{|c|c|c|c|c|c|c|c|c|}
\hline \multirow[t]{3}{*}{ QoL } & \multicolumn{4}{|l|}{ Overall survival } & \multicolumn{4}{|l|}{ Disease-free survival } \\
\hline & \multicolumn{2}{|l|}{$\begin{array}{l}\text { Preoperative QoL } \\
(N=187)\end{array}$} & \multicolumn{2}{|c|}{$\begin{array}{l}\text { QoL } 3 \text { months after surgery } \\
(N=178)\end{array}$} & \multicolumn{2}{|l|}{$\begin{array}{l}\text { Preoperative QoL } \\
(N=187)\end{array}$} & \multicolumn{2}{|c|}{$\begin{array}{l}\text { QoL } 3 \text { months after surgery } \\
(N=178)\end{array}$} \\
\hline & $\mathrm{HR}^{\mathrm{a}}(95 \% \mathrm{CI})$ & $P$ value & $\mathrm{HR}^{\mathrm{a}}(95 \% \mathrm{CI})$ & $P$ value & $\mathrm{HR}^{\mathrm{b}}(95 \% \mathrm{CI})$ & $P$ value & $\mathrm{HR}^{\mathrm{b}}(95 \% \mathrm{CI})$ & $P$ value \\
\hline $\begin{array}{l}\text { SF-20 physical } \\
\text { functioning }\end{array}$ & Not in model & & Not in model & & Not in model & & Not in model & \\
\hline $\begin{array}{r}\text { SF-20 health } \\
\text { perception }\end{array}$ & Not in model & & Not in model & & not in model & & Not in model & \\
\hline $\begin{array}{l}\text { SF-20 social } \\
\text { functioning }\end{array}$ & Not in model & & $\begin{array}{l}0.835 \\
\quad(0.710-0.980)\end{array}$ & 0.035 & Not in model & & Not in model & \\
\hline SF-20 energy & Not in model & & Not in model & & Not in model & & Not in model & \\
\hline SF-20 pain & Not in model & & $\begin{array}{l}1.196 \\
\quad(1.020-1.401)\end{array}$ & 0.026 & Not in model & & $\begin{array}{l}1.321 \\
\quad(1.006-1.022)\end{array}$ & 0.001 \\
\hline $\begin{array}{l}\text { SF-20 role } \\
\text { functioning }\end{array}$ & Not in model & & Not in model & & Not in model & & Not in model & \\
\hline $\begin{array}{l}\text { SF-20 mental } \\
\text { health }\end{array}$ & Not in model & & Not in model & & Not in model & & Not in model & \\
\hline $\begin{array}{l}\text { RSCL physical } \\
\text { symptoms }\end{array}$ & $\begin{array}{l}0.668 \\
\quad(0.470-0.942)\end{array}$ & 0.021 & Not in model & & $\begin{array}{l}0.641 \\
\quad(0.442-0.942)\end{array}$ & 0.024 & Not in model & \\
\hline $\begin{array}{l}\text { RSCL activity } \\
\text { level }\end{array}$ & Not in model & & $\begin{array}{l}0.785 \\
\quad(0.641-0.980)\end{array}$ & 0.037 & Not in model & & $\begin{array}{l}0.724 \\
\quad(0.975-0.992)\end{array}$ & $<0.001$ \\
\hline $\begin{array}{l}\text { RSCL } \\
\text { psychological } \\
\text { symptoms }\end{array}$ & Not in model & & Not in model & & Not in model & & Not in model & \\
\hline $\begin{array}{l}\text { RSCL global } \\
\text { quality of life }\end{array}$ & Not in model & & Not in model & & Not in model & & Not in model & \\
\hline \multicolumn{9}{|l|}{ Clinical } \\
\hline Age [years] & Not in model & & Not in model & & Not in model & & Not in model & \\
\hline Sex (male/female) & Not in model & & Not in model & & Not in model & & Not in model & \\
\hline Weight loss $[\mathrm{kg}]$ & Not in model & & Not in model & & Not in model & & Not in model & \\
\hline Tumor length $[\mathrm{cm}]$ & $\begin{array}{l}1.082 \\
\quad(1.006-1.164)\end{array}$ & 0.034 & Not in model & & $\begin{array}{l}1.112 \\
\quad(1.029-1.198)\end{array}$ & 0.008 & Not in model & \\
\hline \multicolumn{9}{|l|}{ uT-stage } \\
\hline T1 vs. T3 & $\begin{array}{l}0.050 \\
\quad(0.007-0.361)\end{array}$ & 0.003 & NA & & $\begin{array}{l}0.029 \\
\quad(0.0002-0.207)\end{array}$ & $<0.001$ & NA & \\
\hline T2 vs. T3 & $\begin{array}{l}0.912 \\
\quad(0.554-1.501)\end{array}$ & 0.717 & NA & & $0.975(0.585-1.558)$ & 0.918 & NA & \\
\hline $\begin{array}{l}\text { uN-stage } \\
\text { (N1 vs. N0) }\end{array}$ & Not in model & & NA & & Not in model & & NA & \\
\hline \multicolumn{9}{|l|}{ pT-stage } \\
\hline $\mathrm{T} 1$ vs. T3 & NA & & $\begin{array}{l}0.122 \\
\quad(0.041-0.367)\end{array}$ & $<0.001$ & NA & & $\begin{array}{l}0.124 \\
\quad(0.035-0.441)\end{array}$ & 0.001 \\
\hline $\mathrm{T} 2$ vs. T3 & NA & & $\begin{array}{l}0.430 \\
\quad(0.229-0.809)\end{array}$ & 0.009 & NA & & $\begin{array}{l}0.463 \\
\quad(0.232-0.922)\end{array}$ & 0.029 \\
\hline $\begin{array}{l}\text { pN-stage } \\
\text { (N1 vs. N0) }\end{array}$ & NA & & $\begin{array}{l}3.433 \\
\quad(1.798-6.555)\end{array}$ & $<0.001$ & NA & & $\begin{array}{l}3.385 \\
(1.640-6.986)\end{array}$ & 0.001 \\
\hline
\end{tabular}

$H R$ hazard ratio, $C I$ confidence interval, $u$ ultrasonographical, $p$ pathological, $N A$ not applicable, $S F-20$ medical outcomes study short form, RSCL Rotterdam symptom checklist

${ }^{a}$ Hazard ratio provides the likelihood of recurrent disease for a patient with a score of 20 points more than another patient

${ }^{\mathrm{b}}$ Hazard ratio provides the likelihood of recurrent disease for a patient with a score of 20 points more than another patient All variables with a $p$-value $<0.05$ were made bold 
a more aggressive and extensive tumor would result in a lower score on this specific subscale and therefore in worse survival. Postoperative QoL subscales predicting survival seemed to be more related to the recovery from the immobilizing and painful effects of major surgery (social functioning, pain, and activity level). However, it remains unclear whether these surgery-related effects fully account for the prognostic significance of these specific subscales.

In addition to intrinsic differences in pre- and postoperative QoL measurements, clinical applicability would also be quite different. Preoperative QoL measurements have significant additional value in disclosing individual prognosis. Using our multivariate prediction model, it might even be possible to help patients making treatmentrelated decisions. By adding the predictive QoL subscales to conventional staging modalities, a more realistic prognosis can be disclosed, which ensures patients to make well-considered choices.

Postoperative predictive QoL subscales, in combination with pathological tumor stage, can help to reassess individual prognosis. Our data indicate that, in patients who explicitly want to be informed about their prognosis, longitudinal QoL measurements can be useful. The fact that the pain subscale and activity level are such strong predictors for disease-free survival suggests that in the future these measurements might even be used as surveillance modality for recurrent disease; a low score on these subscales could be an indication for further diagnostic imaging.

Few studies have investigated the prognostic value of pretreatment QoL in patients with esophageal cancer. ${ }^{14-16}$ Data from the three available studies support the view that a lower pretreatment score on some of the QoL subscales negatively affects survival, but all three studies consisted of heterogeneous patient populations with both potentially curable and incurable patients. Predictive value of posttreatment QoL subscales has not previously been investigated at all for this group of patients. One study examined the change between baseline QoL subscales and posttreatment QoL subscales, albeit in a relatively small series of patients $(n=38) .{ }^{14}$

The first study by Blazeby et al. investigating prognostic value of QoL for patients with esophageal cancer included 89 patients with disease stage II-IV and used European Organisation for Research and Treatment of Cancer (EORTC) QLQ-C30 and EORTC OES24 QoL questionnaires. ${ }^{14}$ Potentially curative esophagectomy was performed in 55 of the patients; no subgroup analysis was performed using only these patients. The authors found that better pretreatment physical function was associated with longer survival. This corresponds with our results indicating preoperative physical symptoms to be predictive for survival. In that same study the change in emotional function between baseline QoL and the measurement 6 months after treatment was also reported to be significantly predictive for survival, even in a relatively small subgroup of patients $(n=38)$. Corresponding postoperative QoL subscales in the present study (e.g., mental and/or psychological function) did not prove to be independently predictive for survival.

In a study by Chau et al., including over 1,000 mainly metastatic esophageal cancer patients the EORTC QLQC30 questionnaire was used to assess the prognostic value of pretreatment QoL. ${ }^{15}$ Physical function, role function, and global quality of life were found to be independent predictors for survival. Unfortunately, the QoL subscales were only analyzed separately in different multivariate models, each including several clinical factors and one QoL subscale, therefore the possible interrelationship between the QoL subscales remains unclear.

A recently published paper investigating QoL as a predictor for survival, also using the EORTC QLQ-C30, found only preoperative appetite loss to be an independent prognostic factor in patients with gastroesophageal cancer. ${ }^{16}$ Appetite loss is one of the 23 items of which our RSCL physical function subscale is composed. We deliberately chose not to analyze all QoL items separately and only to use subscales, to reduce chance-related findings.

In the present study, a fairly homogeneous patient population of potentially curable patients with esophageal cancer was used. This is in contrast to previous studies consisting of rather heterogeneous patient populations also including locally advanced (T4) and metastatic (M1) tumors. ${ }^{14-16}$ Heterogeneity leads to less precise results for individual prognosis. The restrictive selection criteria that were applied in our study, however, limit its generalizability. Another potential limitation of the present study is that we did not assess the more recently discovered (pathological) predictors, such as extracapsular lymph node involvement. $^{25}$ Furthermore, it is generally accepted to include approximately one variable in multivariate logistic regression analysis for every ten events in the patient population. Therefore, the total number of variables that can be tested is limited. Nevertheless, we did assess the influence of the main comparison of the original randomized trial: although some QoL variables differed significantly 3 months after surgery between the transhiatal and the transthoracic group, including surgical approach as a variable in the multivariate analysis did not influence the prognostic significance of QoL and other variables. ${ }^{22}$

Remarkably, endosonographic N-stage was not a significant predictor for survival in our study, not even on univariate analysis. This is in contrast with previous reports. $^{24,26}$

Most studies investigating preoperative prognostication using QoL also include pathological TNM stage in the multivariate Cox regression models. ${ }^{14-16}$ Since pathological stage is not available preoperatively, we used a more 
realistic approach, including only clinical factors actually available preoperatively.

In conclusion, the results of the present study support the application of predictive QoL subscales in daily clinical practice before and after surgery.

Current guidelines on diagnosis and treatment of esophageal cancer do not recommend any form of postoperative monitoring, while patient preference for disclosure of an individual prognosis is still prominent postoperatively. ${ }^{8}$ Therefore, postoperative predictive QoL subscales combined with pathological TNM stage could be a useful, noninvasive approach to update and improve individual prognosis.

OPEN ACCESS This article is distributed under the terms of the Creative Commons Attribution Noncommercial License which permits any noncommercial use, distribution, and reproduction in any medium, provided the original author(s) and source are credited.

\section{REFERENCES}

1. Graham AJ, Shrive FM, Ghali WA, Manns BJ, Grondin SC, Finley RJ, et al. Defining the optimal treatment of locally advanced esophageal cancer: a systematic review and decision analysis. Ann Thorac Surg. 2007;83(4):1257-64.

2. Gebski V, Burmeister B, Smithers BM, Foo K, Zalcberg J, Simes J. Survival benefits from neoadjuvant chemoradiotherapy or chemotherapy in oesophageal carcinoma: a meta-analysis. Lancet Oncol. 2007;8(3):226-34.

3. Hulscher JB, Tijssen JG, Obertop H, van Lanschot JJ. Transthoracic versus transhiatal resection for carcinoma of the esophagus: a meta-analysis. Ann Thorac Surg. 2001;72(1):306-13.

4. Omloo JM, Lagarde SM, Hulscher JB, Reitsma JB, Fockens P, van Dekken $\mathrm{H}$, et al. Extended transthoracic resection compared with limited transhiatal resection for adenocarcinoma of the mid/ distal esophagus: five-year survival of a randomized clinical trial. Ann Surg. 2007;246(6):992-1000.

5. Orringer MB, Marshall B, Iannettoni MD. Transhiatal esophagectomy: clinical experience and refinements. Ann Surg. 1999; 230(3):392-400.

6. Lagarde SM, ten Kate FJ, Reitsma JB, Busch OR, van Lanschot JJ. Prognostic factors in adenocarcinoma of the esophagus or gastroesophageal junction. J Clin Oncol. 2006;24(26):4347-55.

7. Hagerty RG, Butow PN, Ellis PM, Dimitry S, Tattersall MH. Communicating prognosis in cancer care: a systematic review of the literature. Ann Oncol. 2005;16(7):1005-53.

8. Lagarde SM, Franssen SJ, van W, Jr, Smets EM, Tran TC, Tilanus HW, et al. Patient Preferences for the Disclosure of Prognosis After Esophagectomy for Cancer with Curative Intent. Ann Surg Oncol. 2008;15(11):3289-98.

9. Gotay CC, Kawamoto CT, Bottomley A, Efficace F. The prognostic significance of patient-reported outcomes in cancer clinical trials. J Clin Oncol. 2008;26(8):1355-63.

10. Coates A, Gebski V, Signorini D, Murray P, McNeil D, Byrne M, et al. Prognostic value of quality-of-life scores during chemotherapy for advanced breast cancer. Australian New Zealand Breast Cancer Trials Group. J Clin Oncol. 1992;10(12):1833-8.

11. Maione P, Perrone F, Gallo C, Manzione L, Piantedosi F, Barbera $\mathrm{S}$, et al. Pretreatment quality of life and functional status assessment significantly predict survival of elderly patients with advanced non-small-cell lung cancer receiving chemotherapy: a prognostic analysis of the multicenter Italian lung cancer in the elderly study. J Clin Oncol. 2005;23(28):6865-72.

12. Maisey NR, Norman A, Watson M, Allen MJ, Hill ME, Cunningham D. Baseline quality of life predicts survival in patients with advanced colorectal cancer. Eur J Cancer. 2002;38(10): 1351-7.

13. Sullivan PW, Nelson JB, Mulani PM, Sleep D. Quality of life as a potential predictor for morbidity and mortality in patients with metastatic hormone-refractory prostate cancer. Qual Life Res. 2006;15(8):1297-306.

14. Blazeby JM, Brookes ST, Alderson D. The prognostic value of quality of life scores during treatment for oesophageal cancer. Gut. 2001;49(2):227-30.

15. Chau I, Norman AR, Cunningham D, Waters JS, Oates J, Ross PJ. Multivariate prognostic factor analysis in locally advanced and metastatic esophago-gastric cancer-pooled analysis from three multicenter, randomized, controlled trials using individual patient data. J Clin Oncol. 2004;22(12):2395-403.

16. McKernan M, McMillan DC, Anderson JR, Angerson WJ, Stuart RC. The relationship between quality of life (EORTC QLQ-C30) and survival in patients with gastro-oesophageal cancer. $\mathrm{Br} \mathrm{J}$ Cancer. 2008;98(5):888-93.

17. American Society of Anesthesiologists: ASA physical status classification system. Park Ridge, III: American Society of Anesthesiologists. http://www.asahq.org/clinical/physicalstatus.htm. 2002. Ref Type: Internet Communication. Accessed 10 Oct 2009.

18. Hulscher JB, van Sandick JW, de Boer AG, Wijnhoven BP, Tijssen JG, Fockens $P$, et al. Extended transthoracic resection compared with limited transhiatal resection for adenocarcinoma of the esophagus. N Engl J Med. 2002;347(21):1662-9.

19. Stewart AL, Hays RD, Ware JE, Jr. The MOS short-form general health survey. Reliability and validity in a patient population. Med Care. 1988;26(7):724-35.

20. de Boer AG, van Lanschot JJ, Stalmeier PF, van Sandick JW, Hulscher JB, de Haes JC, et al. Is a single-item visual analogue scale as valid, reliable and responsive as multi-item scales in measuring quality of life? Qual Life Res. 2004;13(2):311-20.

21. de Haes JC, van Knippenberg FC, Neijt JP. Measuring psychological and physical distress in cancer patients: structure and application of the Rotterdam Symptom Checklist. Br J Cancer. 1990;62(6):1034-8.

22. de Boer AG, Genovesi PI, Sprangers MA, van Sandick JW, Obertop H, van Lanschot JJ. Quality of life in long-term survivors after curative transhiatal oesophagectomy for oesophageal carcinoma. Br J Surg. 2000;87(12):1716-21.

23. Heinze G, Schemper M. A solution to the problem of monotone likelihood in Cox regression. Biometrics. 2001;57(1):114-9.

24. Omloo JM, Sloof GW, Boellaard R, Hoekstra OS, Jager PL, van Dullemen HM, et al. Importance of fluorodeoxyglucose-positron emission tomography (FDG-PET) and endoscopic ultrasonography parameters in predicting survival following surgery for esophageal cancer. Endoscopy. 2008;40(6):464-71.

25. Lagarde SM, Reitsma JB, de Castro SM, ten Kate FJ, Busch OR, van Lanschot JJ. Prognostic nomogram for patients undergoing oesophagectomy for adenocarcinoma of the oesophagus or gastro-oesophageal junction. Br J Surg. 2007;94(11):1361-8.

26. Mariette C, Balon JM, Maunoury V, Taillier G, Van SI, Triboulet JP. Value of endoscopic ultrasonography as a predictor of longterm survival in oesophageal carcinoma. Br J Surg. 2003;90(11): $1367-72$ 